\title{
Efficiency of university education: A partial frontier analysis
}

Rafael Antonio Viana*, José M. Arranz** and Carlos García-Serrano***

* Rafael Antonio Viana. Department of Economics. Faculty of Human Sciences. Department of Economics. Universidad Industrial de Santander. Bucaramanga, Santander. Colombia. E-mail: ranviana@ uis.edu.co

** Corresponding author: José M. Arranz. Department of Economics. Faculty of Economics, Business and Tourism. University of Alcalá. Alcalá de Henares, 28802-Madrid, Spain. E-mail: josem.arranz@uah.es

*** Carlos García-Serrano. Department of Economics. Faculty of Economics, Business and Tourism. University of Alcalá Alcalá de Henares 28802-Madrid, Spain. E-mail: carlos.garcia@uah.es

\begin{abstract}
:
This article investigates the efficiency of the university education using two linked databases (Saber Pro and Saber 11) from the Colombian Institute for Evaluation of Education (ICFES) corresponding to 2014. We use a non-parametric frontier approach that combines the "order m" technique with the concept of a meta-frontier to disaggregate students' total efficiency in generic skills in quantitative reasoning, critical reading, and written communication, into the parts attributable to the students themselves and the university. The analysis is performed by academic programme and by education sector (public vs. private). Results indicate that most of the inefficiency of students in the assessment of generic skills in higher education is attributable to the students themselves and a significant number of students could improve their performance in the assessment in each of the academic programmes if they performed as efficiently as those located on the frontier. Furthermore, the inefficiency share of students varies between academic programmes and university sectors, with students in the private sector more inefficient than those in the public sector in some and less inefficient in others. This research constitutes the first application of the technique of "order m" with the approach of the meta-frontier for the analysis of educational efficiency using data at the student and university levels.
\end{abstract}

Keywords: efficiency, tertiary education, order $\mathrm{m}$ and meta-frontier models

JEL Classification: C13, G14, I20, I2 1 


\section{Introduction}

In recent years, a series of indicators has been developed to evaluate and classify educational institutions according to their performance. The evaluation of systems and educational institutions is of great importance for society at large. In the case of public universities, the position occupied in the classification is crucial, because it can determine both the demand for new quotas and the amount of the transfers received from the government. For private universities the issue is no less important, because its place in the classification is also reflected in both the demand for new quotas and the price set for the enrolments.

Parallel to the implementation of indicators and classifications of educational institutions, the debate on the appropriateness of the modelling and interpretation of performance indicators has developed. For that purpose, frontier approaches have been developed in the literature, which are based on the construction of a frontier composed of the most efficient units that serve as a reference for comparisons between the units in the analysis. Among the frontier approaches, the parametric and the non-parametric ones can be distinguished. The parametric frontier method is characterized by the need to specify the functional form of the model. The method that is most used in the analysis of the efficiency of higher education is stochastic frontier analysis (SFA) (see Zoghbi et al., 2013).

Non-parametric frontier methods are most commonly used in the context of educational efficiency analysis because of their flexibility in dealing with multiple products and because they do not need any model specification beforehand. The non-parametric technique commonly used in university efficiency analysis is data envelopment analysis (DEA) proposed by Charnes et al. (1978) and in a smaller proportion the FDH (Deprins et al., 1984). Cazals et al. (2002), propose an original nonparametric estimator of the efficient frontier which is more robust to extreme values, noise or outliers than the standard DEA and FDH nonparametric estimators. this robust technique is called "order m". Similarly, the concept of a meta-frontier Battese \& Rao, 2002; Battese et al., 2004; O'Donnell et al., 2007), for making efficiency comparisons across groups of firms, can also be used for the analysis of efficiency levels in universities.

The main contribution of this paper to the literature is to be the first application of the combination of the "order m" and meta-frontier techniques for the analysis of efficiency at the university level in generic skills in quantitative reasoning, critical reading, and written communication using data from Colombia (the "Saber Pro" test corresponding to 2014), a Latin American country whose educational system has expanded substantially in the last two decades or so. ${ }^{1}$ One of the first studies to apply the technique of "order m" with the approach of the meta-frontier for the analysis of educational efficiency were carried out by De Witte et al. (2010), who evaluated the performance of 3,017 girls in single-sex British schools. Thieme et al. (2013) evaluated the efficiency of a sample of fourth-grade primary students in Chile, and Cordero \& Simancas (2013) analysed the efficiency of Spanish students in the Pisa test in 2009. No previous efficiency analysis has been performed through the integration of approaches (those of "order $\mathrm{m}$ " and the meta-frontier) at the university level. This study constitutes the first attempt to integrate and apply the approaches in the analysis of university efficiency, focusing on Colombia.

The rest of the paper is organized as follows. The second section reviews the approaches and techniques used in university efficiency analysis and the empirical literature based on them. The third section describes the methodology to be used. The fourth section presents the data and the main variables. The fifth section provides and discusses the results of the empirical analysis. The last section contains the main conclusions.

1 The partial frontier technique of "order m" was developed by Cazals et al. (2002) and the concept of a meta-frontier by O’Donnell et al. (2007). 


\section{Literature review}

In the analysis of university efficiency, non-parametric techniques have been used, such as the enveloping analysis of data (DEA) and the semi-parametric analysis of stochastic frontiers (SFA), and parametric measures, such as analysis by ordinary least squares, corrected ordinary least squares, logistic regression and multilevel analysis (ML). Among the techniques, the most used in the literature are the non-parametric DEA (Abramo et al., 2011; Johnes, 2006b; Johnes \& Taylor, 1987) and parametric ML (Johnes, 2006b), for their ease of working with disaggregated data at the individual (student) level.

The DEA technique has significant advantages over the semi-parametric and parametric methods (Diamond \& Medewitz, 1990). The DEA is not sensitive to the choice of the functional form of the model. Contrary to ML, The DEA allows to deal with multiple inputs and outputs and can be used to evaluate the relative efficiency of the decision-making unit (DMU). ${ }^{2}$ The DEA has been widely used in the analysis of university efficiency. In general, university efficiency studies with DEA has been applied to aggregate data (Abramo et al., 2011; Johnes, 2006b; Johnes \& Taylor, 1987). Among the studies that have used data on the disaggregated student level and analysed efficiency in a way, that is, distinguishing the part attributable to the students and the part attributable to the universities Johnes's (2006a) study stands out. This author applied DEA to disaggregated data from 2,547 graduate students of economics in UK universities in 1993 to assess the technical efficiency of university departments of economics; compared the efficiency resulting from the use of data that are not grouped with the efficiency derived from pooled data; and used the methodology proposed by Silva Portela \& Thanassoulis (2001) and Thanassoulis (1999) to separate the portion of the efficiency corresponding to the students and that corresponding to the economics departments. Johnes (2006b) also used disaggregated data for 54,564 students from UK universities to assess whether the technique chosen between multilevel analysis and DEA affects university behaviour.

According to Abbott \& Doucouliagos (2003), there are some limitations in the use of the DEA. The technique identifies two or more DMU that operate on the frontier of best practices. In other words, at least one DMU will be given a score of 1 , when even the best performing DMU may not be operating at the frontier. This can be a problem if all units are inefficient to a certain extent. Secondly, the result is sensitive to the increment of inputs and number of observations, while requiring convexity with respect to production technology.

Like the DEA technique, the Free Disposal Hull approach (FDH) and has been used for the evaluation of efficient techniques Gupta et al., 1997; De White et al., 2010; Diewert \& Fox, 2014). Contrary to the DEA's analysis, the FDH does not require convexity with respect to the production technology and assumes the free disposition of inputs and products. According to Gupta et al. (1997), FDH establishes the production possibility frontier, which represents the combination of the best production results observed in the sample of observations (best practices) and measures the relative inefficiency of producers within the possibility frontier of production given by the distance to the FDH frontier. Deterministic approaches such as DEA and $\mathrm{FDH}$ are sensitive to extreme values and dimensionality in the data. ${ }^{3}$

To overcome the problem of the sensitivity of the DEA and FDH approaches to extreme values and dimensionality, Cazals et al. (2002) proposed the "order m" frontier estimator, related to the FDH approach and based on the maximum expected product (or minimum input). Frontier estimators of "order m" evaluate the observations as a function of a partial frontier rather than a total frontier. They allow statistical inference while maintaining the non-parametric nature. An additional advantage of "order m" estimators is that they allow the comparison

2 A DMU is a unit responsible for converting inputs into products, the actions of which must be evaluated to achieve maximum efficiency. In the present case, it is assumed that each student is a DMU.

3 De Borger et al. (1994) showed that the FDH may be sensitive to both the number and distribution of observations in the data group and the number of dimensions of the products and inputs considered. 
of groups of different sizes, which is very common in the educational context. ${ }^{4}$ In this way, they avoid the bias of results available from DEA efficiency estimates with groups of different sizes (see Zhang \& Bartels, 1998). The procedure for calculating the "order m" estimator is described in Daraio \& Simar (2007).

Finally, the meta-frontier approach, (see Battese \& Rao, 2002; Battese et al., 2004; O'Donnell et al., 2007) allows the measurement of the efficiency of the units evaluated in relation to the separate frontiers of best practices. When students are nested in universities, the approach allows the decomposition of the efficiency of each student into one part attributable to the university and another part attributable to the student himself. The meta-frontier approach is very similar to the approach of Silva Portela \& Thanassoulis (2001) and Thanassoulis et al. (2002), who described two frontiers: a global frontier that defines student efficiency within all schools and a local frontier that defines student efficiency within the students' own school.

\section{Context, data and variables}

\subsection{The Colombian educational context}

The Colombian higher education system is composed of two levels: the degree and the postgraduate level. The degree level is made up of three categories: 'Professional technician' (professional technical programmes) with a duration of 2 years; 'Technological' (technological programmes) with a duration of 3 years; and 'Professional' (university professional programmes) with a duration of between 4 and 5 years. This last category is the focus of the present analysis. The postgraduate level is made up of the sub-levels of 'Specializations' (related to professional technical specialization programmes, technological specialization and professional specializations), 'Master's degrees' and 'Doctorates'. Professional higher education programmes in Colombia are offered by both public and private institutions.

The Colombian government through the Ministry of National Education (MEN) has expressed its concern about the inefficiency in the administration of educational resources, which translates into a profound inequity that is reflected dramatically in the results of students in quality measurement tests such as 'Timss', 'Saber'6 and 'State'

\subsection{Data}

The database used in this study was constructed with information contained in two databases from the Colombian Institute for Evaluation of Education (ICFES). ${ }^{8}$ The first of these, called the "Saber Pro" test, contains the results of an assessment of students' generic skills conducted in the last semester of professional academic programmes in critical reading, written communication, quantitative reasoning, and English. This database corresponds to the year 2014 and contains institutional, family, and personal information about the students. The second database is the "Saber 11" test and contains, among other variables, the results of the evaluation of skills in math, critical, social and civic reading, science, and English carried out with senior high school students.

4 In multilevel analysis and the DEA, groups of different sizes are usually compared without taking into account their difference.

5 Trends in International Mathematics and Science Study (TIMSS) provides reliable and timely data on the mathematics and science achievement of U.S. students compared to that of students in other countries. TIMSS data have been collected from students at grades 4 and 8 since 1995 every 4 years, generally. (see https://nces.ed.gov/timss/).

6 The Saber tests are different tests (Saber 3rd, 5th and 9ht ${ }^{\circ}$, Saber 11 Test, Saber TyT Test, and Saber Pro Test) through which the ICFES evaluates the quality of education in Colombia: https://www.icfes.gov.co/\#.

7 The State tests are standardized tests that the different States apply to evaluate education.

8 The ICFES is the institution responsible for evaluating education in Colombia at all levels. 
The linking of the two databases allows us to obtain a new database that contains the anonymized results of the evaluation of generic competencies in critical reading, written communication, and quantitative reasoning of 103,759 students in the "Saber Pro" test and anonymized results of evaluating skills in math and critical reading in the standardized "Saber 11" test of these same students.

Since related university academic programmes were added by the ICFES to reference groups, and taking into account that both public and private universities do not offer academic programmes of all groups, this analysis of university efficiency is performed by reference group (academic programme) and type of university (public or private). ${ }^{9}$ After selecting the value of " $\mathrm{m}$ ", according to the number of students per reference group and university, the initial data were reduced to 93,943 observations, which correspond to the total of the sample used in the analysis. Of this total, 36,181 observations correspond to students belonging to public universities and 57,762 to students in private universities.

Tables 1 and 2 provide the reference groups into which the professional academic programmes were grouped, students by group, universities with at least one academic programme in the reference group, and the "order m" selected by agreement with the reference group. The value of the selected " $\mathrm{m}$ " is equal by reference group for both public and private sector universities. This selection was made taking into account that the institutions included in a given reference group would have a suitable number of students (minimum) to be able to contrast the efficiency of the reference groups between the public and the private sector.

Table 1 shows that 36,181 observations pertaining to students enrolled in public universities were grouped into 342 university units. Thus, a total of 342 partial frontiers are estimated in the efficiency analysis of public universities. The number of university units (UU) responds to the fact that the analysis is carried out by reference group and therefore educational institutions that offer academic programmes belonging to each of the reference groups under study and with a number of students that were tested in the standardized "Saber Pro" test in 2014 that is equal to or greater than " $m$ " value selected by the reference group. The analysis will have 17 university units and so on. ${ }^{10}$

Engineering, administration, and education, with $12.6 \%, 11.4 \%$, and $9.1 \%$, respectively, are the reference groups with the largest university participation units in the sample in public universities (see Table 1). This evidence shows that these reference groups have the largest offer of programmes in the public university sector in Colombia with more than half. In addition, the engineering, education, and administration groups account for $30.4 \%, 18 \%$, and $10.9 \%$, respectively. As for the reference groups with the fewest university units in the sample, the humanities and architecture stand out with $1.2 \%$ and $1.4 \%$, respectively. The fact that the university units of engineering and related subjects, administration, and education have the largest number of students in the sample is due to these groups being made up of a considerable number of academic programmes, which are offered in more than $90 \%$ of the country's public universities. The results also show a clear positive correlation between the number of UUs and the number of students per reference group.

Table 2 displays the same information as before for private universities. In this case, the reference groups of administration, engineering, law, and accounting have the highest percentage of decision-making unit (DMUs) in the analysis, with 14.3\%, 11.5\%, 10.1\%, and 9.6\%, respectively. Likewise, the first three reference groups named together account for $52 \%$ of the students in the sample corresponding to the private university sector.

9 The grouping of university academic programmes into reference groups is included in Annex 1.

10 According to the Ministry of Education, there are 82 institutions offering at least one professional programme. 
Table 1. Reference groups, students and decision unit's public universities.

\begin{tabular}{|c|c|c|c|c|c|}
\hline & \multicolumn{2}{|c|}{ Students } & \multicolumn{2}{|c|}{ Universities } & \multirow[t]{2}{*}{ Order m } \\
\hline & No. & $\%$ & No. & $\%$ & \\
\hline Administration and related & 3,935 & 10.9 & 39 & 11.4 & 30 \\
\hline Architecture & 514 & 1.4 & 9 & 2.6 & 17 \\
\hline Fine arts and design & 674 & 1.9 & 13 & 3.8 & 25 \\
\hline Agricultural Sciences & 933 & 2.6 & 19 & 5.6 & 17 \\
\hline Natural and exact sciences & 1,442 & 4.0 & 25 & 7.3 & 16 \\
\hline Social Sciences & 1,628 & 4.5 & 22 & 6.4 & 16 \\
\hline Communication and journalism & 435 & 1.2 & 11 & 3.2 & 20 \\
\hline Accountancy and related & 2,358 & 6.5 & 26 & 7.6 & 30 \\
\hline Law & 1,726 & 4.8 & 19 & 5.6 & 35 \\
\hline Economics & 824 & 2.3 & 17 & 5.0 & 20 \\
\hline Education & 6,523 & 18.0 & 31 & 9.1 & 30 \\
\hline Nursing & 818 & 2.3 & 18 & 5.3 & 20 \\
\hline Humanities & 429 & 1.2 & 9 & 2.6 & 14 \\
\hline Engineering & 10,995 & 30.4 & 43 & 12.6 & 50 \\
\hline Medicine & 839 & 2.3 & 14 & 4.1 & 20 \\
\hline Psychology & 717 & 2.0 & 12 & 3.5 & 20 \\
\hline Health & 1,391 & 3.8 & 15 & 4.4 & 30 \\
\hline Total & 36,181 & 100 & 342 & 100 & \\
\hline
\end{tabular}

Source: ICFES, own elaboration

Table 2. Reference groups, students and decision unit's private universities.

\begin{tabular}{lrrrrr}
\hline & \multicolumn{2}{c}{ Students } & \multicolumn{2}{c}{ Universities } & Order m \\
\hline & \multicolumn{1}{c}{ No. } & \multicolumn{1}{c}{$\%$} & \multicolumn{1}{c}{ No. } & $\%$ & \\
Administration and related & 11,522 & 20.0 & 82 & 14.3 & 35 \\
Architecture & 1,625 & 2.8 & 20 & 3.5 & 20 \\
Fine arts and design & 2993 & 5.0 & 31 & 5.4 & 25 \\
Agricultural Sciences & 672 & 1.2 & 13 & 2.3 & 17 \\
Natural and exact sciences & 336 & 0.6 & 6 & 1.1 & 16 \\
Social Sciences & 1,655 & 2.9 & 18 & 3.2 & 20 \\
Communication and journalism & 4,600 & 8.0 & 41 & 7.2 & 20 \\
Accountancy and related & 4,375 & 7.6 & 55 & 9.6 & 30 \\
Law & 7,204 & 12.5 & 58 & 10.1 & 35 \\
Economics & 931 & 1.6 & 20 & 3.5 & 20 \\
Education & 1,753 & 3.0 & 22 & 3.9 & 30 \\
Nursing & 1,646 & 2.9 & 25 & 4.4 & 20 \\
Humanities & 228 & 0.4 & 5 & 0.8 & 14 \\
Engineering & 12,059 & 19.6 & 66 & 11.5 & 50 \\
Medicine & 2,710 & 4.7 & 31 & 5.4 & 20 \\
Psychology & 3,374 & 5.8 & 45 & 7.9 & 20 \\
Health & 3,072 & 5.3 & 34 & 6.2 & 20 \\
Total & 57,762 & 100 & 601 & 100 & \\
\hline
\end{tabular}

Source: ICFES, own elaboration

Reference groups such as those in the humanities, natural sciences, and exact sciences, despite being supported by more than 6 and 8 academic programmes, respectively, record the lowest percentage of both DMUs and students in the sample corresponding to the private university sector, with $0.8 \%$ and $1.1 \%$ of decision units and $0.4 \%$ and $0.6 \%$ for students, respectively. The main cause of this result is both the low supply of academic programmes belonging to these 
reference groups in private universities and the low level of interest on the part of the students in attending the academic programmes in the reference groups. We also find that reference groups that are made up of a single academic programme, such as psychology and accounting, register a considerable percentage of both DMUs $(7.9 \%$ and $9.6 \%)$ and students in the sample $(5.8 \%$ and $7.6 \%$ ), which is due to the wide range of these programmes in the private sector.

\subsection{Variables}

According to Chakraborty (2009), one of the main drawbacks in the analysis of educational efficiency concerns the appropriate choice of educational product measure. For Ahn et al. (1988), there is general agreement that higher education products should be based on the results of teaching, research, and community services (consultancies and/or advisory services). In efficiency analyses that focus their attention on the results of university education, the products are usually represented by the number of graduates (Johnes \& Taylor, 1987; Johnes, 2006a, 2006b; Kuah \& Wong, 2011) and/or standardized test results (Black \& Duhon, 2003). In our analysis of the efficiency of university education in Colombia, we use as output measures of university education the results of students in standardized assessments of generic skills in quantitative reasoning, critical reading, and written communication from the "Saber Pro" test per student.

Among the variables or factors that affect the quality of higher education, the academic achievements made by students before entering university have been recognized as the most important factor (Kuah \& Wong, 2011; Rodgers \& Ghosh, 2001). ${ }^{11}$ These achievements are represented through the record of the grade (or average grade) obtained by students in their high school studies, standardized tests of academic ability at the end of such studies, or university admission tests.

In this study, we use as input variables the scores obtained by students in the "Saber 11 " standardized tests assessing skills in math and critical reading. Table 3 provides the values of inputs and outputs used for efficient analysis of the public and private sector: it shows the mean scores of the three output variables and the two inputs selected for the efficient analysis of public and private university education in Colombia.

In relation to the analysis for the public university education, the medicine reference group registers the highest mean scores both in the output and input variables. The main reason is the higher level of demand in the university admission process presented by the academic programme that forms this group compared with the programmes that make up the rest of the reference groups. It is also still surprising that the reference medical group shows higher mean scores for the competencies output variable in quantitative reasoning than, for example, the engineering group and related groups. Given the training in quantitative areas that students of the latter group receive, one would expect these to obtain a higher score. The training brought by medical students from their high school studies could influence the result. Other results in public universities that attract attention concern the fact that students from the education reference group recorded the lowest average scores in both the input variables (46.8 in math competition and 49.1 in critical reading) and the output variables (quantitative reasoning skills, 87.8, and critical reading, 90.4). This behaviour shows that academic programmes belonging to this reference group have lower levels of demand in university admission processes than programmes that belong to other groups and references.

As regards the results for private universities, the engineering reference group and related programmes have one of the highest average score in the output variable in quantitative reasoning. This value is in line with the expectations given the training that students pursuing academic programmes belonging to the control group receive. Similarly, the reference group

11 Although the literature recognizes that other variables different from previous academic achievements may affect the performance of university students, in the present study, and due to the availability of data, we follow Johnes (2006b) and De Witte et al. (2010), who use the previous academic achievements of the students as the main input variables. 
of humanities shows the highest average scores for the output variables, critical reading, and written skills. The mean scores recorded by the group of humanities could also result from the training that the students receive during their studies, the students of academic programmes such as philosophy, literature, Spanish, and classical philology, among others, forming such a reference group.

Table 3. Outputs and inputs in public universities.

\begin{tabular}{|c|c|c|c|c|c|c|c|c|c|c|}
\hline & \multicolumn{6}{|c|}{ Outputs } & \multicolumn{4}{|c|}{ Inputs } \\
\hline & \multicolumn{2}{|c|}{$\begin{array}{l}\text { Quantitative } \\
\text { reasoning }\end{array}$} & \multicolumn{2}{|c|}{ Critical reading } & \multicolumn{2}{|c|}{$\begin{array}{c}\text { Written } \\
\text { communication }\end{array}$} & \multicolumn{2}{|c|}{ Maths } & \multicolumn{2}{|c|}{$\begin{array}{l}\text { Critical } \\
\text { reading }\end{array}$} \\
\hline & Public & Private & Public & Private & Public & Private & Public & Private & Public & Private \\
\hline $\begin{array}{l}\text { Administration } \\
\text { and related }\end{array}$ & 91.6 & 91.2 & 93.4 & 90.1 & 95.2 & 94.3 & 49.8 & 49.6 & 50.3 & 50.2 \\
\hline Architecture & 92.6 & 91.0 & 94.0 & 91.5 & 95.1 & 93.2 & 54.7 & 53.0 & 52.5 & 51.4 \\
\hline $\begin{array}{l}\text { Fine arts and } \\
\text { design }\end{array}$ & 90.6 & 90.8 & 94.3 & 92.3 & 96.6 & 94.1 & 53.5 & 52.2 & 53.3 & 52.4 \\
\hline $\begin{array}{l}\text { Agricultural } \\
\text { Sciences }\end{array}$ & 94.5 & 90.9 & 91.1 & 90.7 & 93.6 & 94.2 & 49.9 & 47.6 & 50.3 & 48.6 \\
\hline $\begin{array}{l}\text { Natural and } \\
\text { exact sciences }\end{array}$ & 98.9 & 95.3 & 94.4 & 99.4 & 96.3 & 98.1 & 54.5 & 57.6 & 52.5 & 55.2 \\
\hline $\begin{array}{l}\text { Social } \\
\text { Sciences }\end{array}$ & 89.7 & 88.4 & 95.5 & 92.1 & 98.8 & 98.7 & 49.0 & 49.2 & 51.4 & 51.2 \\
\hline $\begin{array}{l}\text { Communica- } \\
\text { tion and jour- } \\
\text { nalism }\end{array}$ & 90.2 & 89.4 & 96.6 & 92.7 & 93.7 & 95.3 & 49.2 & 48.9 & 52.3 & 51.1 \\
\hline $\begin{array}{l}\text { Accountancy } \\
\text { and related }\end{array}$ & 91.9 & 89.9 & 91.1 & 87.5 & 94.3 & 93.5 & 50.3 & 47.5 & 50.1 & 48.7 \\
\hline Law & 90.6 & 90.3 & 96.0 & 93.7 & 98.7 & 96.5 & 50.7 & 48.8 & 52.3 & 50.8 \\
\hline Economics & 94.2 & 97.4 & 97.1 & 98.1 & 96.2 & 97.6 & 54.3 & 58.1 & 52.1 & 54.6 \\
\hline Education & 87.8 & 85.5 & 90.4 & 87.2 & 95.9 & 93.3 & 46.8 & 44.2 & 49.1 & 47.3 \\
\hline Nursing & 91.5 & 86.0 & 93.4 & 86.3 & 94.7 & 91.2 & 50.2 & 44.9 & 51.4 & 47.5 \\
\hline Humanities & 92.3 & 92.2 & 97.8 & 99.2 & 99.2 & 103.5 & 50.2 & 55.3 & 53.2 & 55.5 \\
\hline Engineering & 97.6 & 95.5 & 95.0 & 92.5 & 94.7 & 94.0 & 55.6 & 53.9 & 52.3 & 51.2 \\
\hline Medicine & 101.4 & 93.9 & 102.3 & 93.9 & 100.0 & 95.2 & 62.2 & 52.5 & 58.0 & 53.0 \\
\hline Psychology & 90.1 & 88.7 & 97.3 & 92.9 & 98.0 & 97.6 & 49.1 & 47.2 & 52.0 & 50.1 \\
\hline Health & 94.4 & 87.5 & 94.5 & 87.9 & 96.3 & 94.6 & 51.3 & 46.5 & 52.2 & 48.7 \\
\hline
\end{tabular}

Source: ICFES, own elaboration.

Note: Output measures refer to the results of students in standardized assessments of generic skills in quantitative reasoning, critical reading and written communication from the "Saber Pro" test. Input variables refer to the scores obtained by students in the "Saber 11 " standardized tests assessing skills in math and critical reading.

As for inputs, the education reference group shows the lowest scores in both math and language skills. As discussed in the case of the public university sector, this result may be due to lower levels of demand in the admissions process for students of the academic programmes that make up this reference group than for students of other programmes that make up reference groups. 


\section{Results}

Results of the estimation procedure distinguishing by education sector are provided in this section. We first present the results corresponding to the public universities, then those of the private universities, and finally both are compared. Table 4 provides the estimated model " $\mathrm{m}$ " results for each reference group into which the ICFES grouped professional academic programmes. These results refer to the public and private universities Estimations are carried out using the Software R, through the FEAR package.

\subsection{Efficiency analysis in public universities}

Based on the information presented in Table 3 and following the methodology of Silva Portela \& Thanassoulis (2001) and Thanassoulis et al. (2002), the overall efficiency (OE) of each reference group is decomposed into a part attributable to the student (SE) and another part attributable to universities (UE). According to the decomposition of efficiency, Table 4 contains three rows that show the decomposition of the efficiency $(\mathrm{EC})$ : the total or overall efficiency $(\mathrm{OE})$, the one attributable to the students (students efficiency, SE) and the one attributable to the university (university efficiency, UE).

In terms of OE, students belonging to the reference group of agricultural sciences recorded the highest average efficiency score of 1.053. Given that scores above the unit in non-parametric analysis are classified as inefficient, the result shows that, if all students perform as efficiently as those located on the curve of best practices, the score in the products analysed should increase on average by about $5.3 \%$. According to the breakdown of inefficiency, of this percentage, $3.5 \%$ are SE. This value shows that, by controlling past achievements and as a reference to students located on the frontier of best practices, with a greater effort these students may increase the average score by $3.5 \%$. Similarly, the part of the inefficiency attributable to public universities is on average $1.8 \%$. This result suggests that, given the characteristics of the academic programmes that make up the group of agricultural sciences, students achieve a lower than expected performance. Furthermore, only $25 \%$ of students (quartile 1 ) who enrolled in an academic programme related to agricultural science achieve a performance between efficient and super-efficient (the efficiency value is less than the unit) in the "Saber Pro" tests in the three products tested, a result that is similar to others found in almost all reference groups.

With regard to the OE of the reference group of engineering and related studies, Table 4 shows that the overall inefficiency of students is $4.3 \%$, indicating that if all students performed as efficiently as those located on the border, their average (geometric) scores should improve by the same percentage. ${ }^{12}$ Of the percentage of the overall inefficiency of students belonging to the reference group of engineering and related programmes, the highest percentage corresponds to the students, with $3.6 \%$. The estimated average inefficiency corresponding to the universities with academic programmes belonging to the same reference group was 1.007 , which is tantamount to saying that the average inefficiency attributable to the universities is less than $1 \%(0.7 \%)$. This result largely shows that on average better student performance is subject to greater effort. It is also noted that in this group $25 \%$ of students (quartile 1) have super-efficient performance.

The estimated (geometric) OE average of the reference group of natural and exact sciences is 0.987. Since this score is less than 1, on average students have a super-efficient performance. The $\mathrm{SE}$ average is 1.003. Although this score is slightly above the unit, in percentage terms is $0.3 \%$. We may conclude that students belonging to the reference group used their inputs efficiently. As for the contribution of universities to the $\mathrm{OE}$, the estimated average value is 0.984 . This value shows that, given the characteristics of the academic programmes that constitute efficient groups in the area of natural sciences, there is a group of students with a higher performance than expected considering the institutional characteristics. Finally, at least $50 \%$ (the second quartile) of the students in this group have a super-efficient performance.

12 This is the group with the highest percentage of both students and decision units in the analysis of the efficiency of public higher education $(30.4 \%$ and $12.6 \%$, respectively). 
Table 4. Results of model efficiency for public universities.

Public

\begin{tabular}{|c|c|c|c|c|c|}
\hline Reference Group & E.C. & Mean & 1st quartile & 2st quartile & 3st quartile \\
\hline \multirow{3}{*}{ Administration \& related } & $\mathrm{OE}$ & 1.028 & 0.981 & 1.022 & 1.068 \\
\hline & $\mathrm{SE}$ & 1.024 & 1.017 & 1.023 & 1.027 \\
\hline & UE & 1.004 & 0.954 & 1.004 & 1.057 \\
\hline \multirow{3}{*}{ Architecture \& urban } & $\mathrm{OE}$ & 1.004 & 0.965 & 0.997 & 1.040 \\
\hline & SE & 1.011 & 0.990 & 1.000 & 1.028 \\
\hline & $\mathrm{UE}$ & 0.994 & 0.947 & 0.994 & 1.039 \\
\hline \multirow{3}{*}{ Fine arts \& design } & $\mathrm{OE}$ & 1.011 & 0.965 & 1.003 & 1.049 \\
\hline & $\mathrm{SE}$ & 1.015 & 0.993 & 1.000 & 1.028 \\
\hline & UE & 0.996 & 0.944 & 1.000 & 1.048 \\
\hline \multirow{3}{*}{ Agricultural Sciences } & $\mathrm{OE}$ & 1.053 & 0.999 & 1.048 & 1.109 \\
\hline & SE & 1.035 & 0.997 & 1.018 & 1.071 \\
\hline & $\mathrm{UE}$ & 1.018 & 0.957 & 1.089 & 1.089 \\
\hline \multirow{3}{*}{ Natural \& exact sciences } & $\mathrm{OE}$ & 0.987 & 0.949 & 0.983 & 1.025 \\
\hline & $\mathrm{SE}$ & 1.003 & 0.985 & 1.000 & 1.019 \\
\hline & UE & 0.984 & 0.939 & 0.981 & 1.030 \\
\hline \multirow{3}{*}{ Social Sciences } & $\mathrm{OE}$ & 1.008 & 0.963 & 1.002 & 1.049 \\
\hline & SE & 1.014 & 0.990 & 1.000 & 1.031 \\
\hline & $\mathrm{UE}$ & 0.994 & 0.947 & 0.996 & 1.044 \\
\hline \multirow{3}{*}{ Communication \& journalism } & $\mathrm{OE}$ & 1.020 & 0.978 & 1.008 & 1.053 \\
\hline & $\mathrm{SE}$ & 1.021 & 0.996 & 1.000 & 1.033 \\
\hline & UE & 0.999 & 0.958 & 1.000 & 1.014 \\
\hline \multirow{3}{*}{ Accountancy \& related } & $\mathrm{OE}$ & 1.024 & 0.980 & 1.017 & 1.066 \\
\hline & SE & 1.019 & 0.994 & 1.000 & 1.040 \\
\hline & $\mathrm{UE}$ & 1.005 & 0.955 & 1.006 & 1.060 \\
\hline \multirow{3}{*}{ Law } & $\mathrm{OE}$ & 1.026 & 0.981 & 1.012 & 1.064 \\
\hline & $\mathrm{SE}$ & 1.025 & 0.998 & 1.000 & 1.045 \\
\hline & UE & 1.002 & 0.952 & 1.000 & 1.054 \\
\hline \multirow{3}{*}{ Economics } & $\mathrm{OE}$ & 1.001 & 0.962 & 0.997 & 1.038 \\
\hline & SE & 1.011 & 0.993 & 1.000 & 1.021 \\
\hline & $\mathrm{UE}$ & 0.990 & 0.944 & 0.993 & 1.038 \\
\hline \multirow{3}{*}{ Education } & $\mathrm{OE}$ & 1.023 & 0.971 & 1.016 & 1.068 \\
\hline & $\mathrm{SE}$ & 1.023 & 0.989 & 1.006 & 1.052 \\
\hline & UE & 1.000 & 0.944 & 1.000 & 1.060 \\
\hline \multirow{3}{*}{ Nursing } & $\mathrm{OE}$ & 1.023 & 0.982 & 1.020 & 1.061 \\
\hline & $\mathrm{SE}$ & 1.013 & 0.994 & 1.000 & 1.030 \\
\hline & $\mathrm{UE}$ & 1.009 & 0.964 & 1.009 & 1.060 \\
\hline \multirow{3}{*}{ Humanities } & $\mathrm{OE}$ & 0.999 & 0.953 & 0.993 & 1.036 \\
\hline & $\mathrm{SE}$ & 1.012 & 0.982 & 0.999 & 1.029 \\
\hline & UE & 0.987 & 0.940 & 0.992 & 1.042 \\
\hline \multirow{3}{*}{ Engineering } & $\mathrm{OE}$ & 1.043 & 0.991 & 1.035 & 1.086 \\
\hline & $\mathrm{SE}$ & 1.036 & 0.997 & 1.018 & 1.066 \\
\hline & UE & 1.007 & 0.949 & 1.008 & 1.070 \\
\hline \multirow{3}{*}{ Medicine } & $\mathrm{OE}$ & 1.003 & 0.965 & 1.000 & 1.042 \\
\hline & $\mathrm{SE}$ & 1.010 & 0.990 & 1.000 & 1.026 \\
\hline & $\mathrm{UE}$ & 0.993 & 0.944 & 0.995 & 1.044 \\
\hline \multirow{3}{*}{ Psychology } & $\mathrm{OE}$ & 1.006 & 0.969 & 1.000 & 1.049 \\
\hline & $\mathrm{SE}$ & 1.008 & 0.989 & 1.000 & 1.025 \\
\hline & $\mathrm{UE}$ & 0.998 & 0.952 & 0.997 & 1.053 \\
\hline \multirow{3}{*}{ Health } & $\mathrm{OE}$ & 1.022 & 0.983 & 1.017 & 1.066 \\
\hline & $\mathrm{SE}$ & 1.020 & 0.996 & 1.000 & 1.040 \\
\hline & UE & 1.002 & 0.953 & 1.003 & 1.056 \\
\hline
\end{tabular}

Source: own elaboration.

Note: E.C. means efficiency component. 
Table 4. (continued) Results of model efficiency for private universities.

\begin{tabular}{|c|c|c|c|c|c|}
\hline \multirow[b]{2}{*}{ Reference Group } & \multirow[b]{2}{*}{ E. C. } & \multicolumn{4}{|c|}{ Private } \\
\hline & & Mean & 1st quartile & 2st quartile & 3st quartile \\
\hline \multirow{3}{*}{ Administration \& related } & $\mathrm{OE}$ & 1.031 & 0.983 & 1.025 & 1.072 \\
\hline & $\mathrm{SE}$ & 1.027 & 0.995 & 1.007 & 1.053 \\
\hline & UE & 1.003 & 0.949 & 1.004 & 1.064 \\
\hline \multirow{3}{*}{ Architecture \& urban } & $\mathrm{OE}$ & 1.047 & 0.987 & 1.038 & 1.098 \\
\hline & $\mathrm{SE}$ & 1.009 & 0.983 & 1.000 & 1.025 \\
\hline & UE & 1.038 & 0.981 & 1.035 & 1.093 \\
\hline \multirow{3}{*}{ Fine arts \& design } & $\mathrm{OE}$ & 1.015 & 0.970 & 1.008 & 1.053 \\
\hline & $\mathrm{SE}$ & 1.021 & 0.990 & 1.000 & 1.046 \\
\hline & UE & 0.994 & 0.942 & 0.996 & 1.049 \\
\hline \multirow{3}{*}{ Agricultural Sciences } & $\mathrm{OE}$ & 1.003 & 0.967 & 0.997 & 1.035 \\
\hline & SE & 1.008 & 0.989 & 1.000 & 1.021 \\
\hline & UE & 0.995 & 0.949 & 0.993 & 1.041 \\
\hline \multirow{3}{*}{ Natural \& exact sciences } & $\mathrm{OE}$ & 0.988 & 0.958 & 0.990 & 1.020 \\
\hline & $\mathrm{SE}$ & 1.002 & 0.982 & 1.000 & 1.016 \\
\hline & UE & 0.986 & 0.949 & 0.985 & 1.031 \\
\hline \multirow{3}{*}{ Social Sciences } & $\mathrm{OE}$ & 1.001 & 0.954 & 0.999 & 1.043 \\
\hline & $\mathrm{SE}$ & 1.015 & 0.987 & 1.000 & 1.037 \\
\hline & UE & 0.986 & 0.931 & 0.988 & 1.043 \\
\hline \multirow{3}{*}{ Communication \& journalism } & $\mathrm{OE}$ & 1.008 & 0.962 & 1.002 & 1.046 \\
\hline & $\mathrm{SE}$ & 1.011 & 0.981 & 1.000 & 1.035 \\
\hline & UE & 0.997 & 0.942 & 0.997 & 1.054 \\
\hline \multirow{3}{*}{ Accountancy \& related } & $\mathrm{OE}$ & 1.029 & 0.983 & 1.024 & 1.073 \\
\hline & SE & 1.022 & 0.996 & 1.000 & 1.046 \\
\hline & UE & 1.007 & 0.956 & 1.007 & 1.064 \\
\hline \multirow{3}{*}{ Law } & $\mathrm{OE}$ & 1.024 & 0.977 & 1.018 & 1.068 \\
\hline & $\mathrm{SE}$ & 1.024 & 0.995 & 1.002 & 1.051 \\
\hline & $\mathrm{UE}$ & 1.000 & 0.948 & 1.001 & 1.056 \\
\hline \multirow{3}{*}{ Economics } & $\mathrm{OE}$ & 1.000 & 0.960 & 0.998 & 1.038 \\
\hline & $\mathrm{SE}$ & 1.010 & 0.990 & 1.000 & 1.025 \\
\hline & $\mathrm{UE}$ & 0.990 & 0.946 & 0.991 & 1.037 \\
\hline \multirow{3}{*}{ Education } & $\mathrm{OE}$ & 1.024 & 0.982 & 1.017 & 1.067 \\
\hline & $\mathrm{SE}$ & 1.017 & 0.994 & 1.000 & 1.037 \\
\hline & $\mathrm{UE}$ & 1.007 & 0.958 & 1.011 & 1.062 \\
\hline \multirow{3}{*}{ Nursing } & $\mathrm{OE}$ & 1.016 & 0.974 & 1.010 & 1.054 \\
\hline & $\mathrm{SE}$ & 1.017 & 0.993 & 1.000 & 1.035 \\
\hline & $\mathrm{UE}$ & 1.000 & 0.950 & 0.997 & 1.051 \\
\hline \multirow{3}{*}{ Humanities } & $\mathrm{OE}$ & 0.988 & 0.947 & 0.991 & 1.029 \\
\hline & $\mathrm{SE}$ & 1.003 & 0.985 & 1.000 & 1.022 \\
\hline & UE & 0.985 & 0.935 & 0.985 & 1.033 \\
\hline \multirow{3}{*}{ Engineering } & $\mathrm{OE}$ & 1.035 & 0.986 & 1.029 & 1.078 \\
\hline & $\mathrm{SE}$ & 1.032 & 0.997 & 1.011 & 1.059 \\
\hline & UE & 1.003 & 0.949 & 1.006 & 1.062 \\
\hline \multirow{3}{*}{ Medicine } & $\mathrm{OE}$ & 1.006 & 0.962 & 1.001 & 1.044 \\
\hline & $\mathrm{SE}$ & 1.013 & 0.988 & 1.000 & 1.033 \\
\hline & UE & 0.993 & 0.943 & 0.995 & 1.047 \\
\hline \multirow{3}{*}{ Psychology } & $\mathrm{OE}$ & 1.009 & 0.968 & 1.005 & 1.048 \\
\hline & $\mathrm{SE}$ & 1.011 & 0.988 & 1.000 & 1.031 \\
\hline & UE & 0.998 & 0.951 & 1.000 & 1.050 \\
\hline \multirow{3}{*}{ Health } & $\mathrm{OE}$ & 1.017 & 0.977 & 1.014 & 1.056 \\
\hline & $\mathrm{SE}$ & 1.017 & 0.994 & 1.000 & 1.035 \\
\hline & UE & 1.000 & 0.955 & 1.003 & 1.051 \\
\hline
\end{tabular}




\subsection{Efficiency analysis for private universities}

The average value of the sample SE belonging to the architecture reference group is $1.047 \mathrm{in}$ the private university. This value shows that, if all students perform as efficiently as students located on the frontier of best practices, their score for the evaluated products should increase by $4.7 \%$. By analysing the composition of $\mathrm{OE}$, the greatest contribution to inefficiency that corresponds to universities is $3.8 \%$. Similarly, the contribution of students to the OE is less than $1 \%$. For the administration and related programmes reference group, the value of the estimated $\mathrm{OE}$ on average of each student in the sample is 1.031 The greatest contribution to the OE is made by the students, being approximately $2.7 \%$. This shows that, given their academic abilities, some students could have performed better in the evaluation of generic skills in the "Saber Pro" test. The contribution of universities to the UE is only $0.3 \%$, which means that institutions are meeting their objectives in terms of teaching.

As in the public university sector, the average $\mathrm{OE}$ in private universities belonging to the reference group of natural and exact sciences is less than 1 . The value of 0.988 shows that on average students who belong to that reference group are super-efficient. The analysis of the contribution of efficiency made by the students themselves and the universities shows that the students use their resources fully, since the value of the estimated average SE is 1.002. The estimated value of the average UE is 0.986 , which is similar to the total.

\subsection{Efficiency of public universities compared with private universities}

Since the " $m$ " order selected by reference group is equal both in the public and in the private university sector, we may test the efficiency among sectors for a specific reference group. The information contained in Table 4 shows that the mean OE value of students in the sample belonging to the reference group of administration and related programmes of the public university sector is slightly lower than that in the private sector, $1.028(2.8 \%)$, compared with $1.031(3.1 \%)$. According to these values, the students in the private sector are more inefficient than those in the public sector. Decomposing the overall inefficiency, it is found that most of the inefficiency is due to the students themselves. The SE average value of the public universities is $2.4 \%$, while is $2.7 \%$ in the private sector. As for the part of the inefficiency that is attributable to the universities, it is similar in the two sectors: $0.4 \%$ for the public sector versus $0.3 \%$ for the private sector. Thus, it can be said that the inefficiency of students enrolled in academic programmes in administration and related programmes is an issue that has more to do with the skills of the students themselves than with the characteristics of the institutions where they carry out their studies.

On the other hand, comparing the students' efficiency in the sample belonging to the group of engineering and related programmes in the public university sector versus the private sector, the $\mathrm{OE}$ average value of the former is 1.043 and that of the latter is 1.035. These values show that students in the public university sector are on average almost $0.82 \%$ more inefficient than those in the private sector. Decomposing the overall average inefficiency, both the part of the $\mathrm{SE}(3.6 \%$ vs. $3.2 \%)$ and that corresponding to the UE $(0.7 \%$ vs. 0.3$)$, it is greater in the public university sector than in the private sector. Given this value and taking into account the personal skills and institutional characteristics, it is necessary for students in both sectors to make a greater effort to improve their performance.

In the economics reference group, which consists of a single academic programme, the value of the average $\mathrm{OE}$ of students is very similar for both the public and the private sector. The mean value of the $\mathrm{OE}$ is 1 in the public and private universities, these values showing that students in both sectors on average have an efficient performance. In fact, the data for the second quartile show that at least $50 \%$ of students from both groups have a super-efficient performance. When the overall average efficiency of students in both sectors is decomposed into its components (students and universities), we observe that students from the private sector contribute in a better way to the overall average efficiency than public school students. While 
the average efficiency value is 1.001 for the former, the students of the public sector achieve 1.011. These values show that, controlling for past achievements, the reference group students of economics from the public university sector on average can improve their score on the three products tested by $1.1 \%$ with increased effort. Regarding the contribution of UE there is no difference between the universities of the sectors in question.

Both the public and private university sectors contain six reference groups in which at least $50 \%$ (second quartile) of the students recorded behaviour between super-efficient and efficient. In the public sector, the students belong to the architecture, nature, economics, humanities, medicine, and psychology reference groups. Private students belong to the agricultural sciences, natural sciences, social sciences, economics, humanities, and medicine groups, which comprise up to $50 \%$ (second quartile) of the students.

\section{Conclusions}

This paper has made use of the non-parametric frontier approach to evaluate the performance of university students of professional academic programmes using two databases from the Colombian Institute for Evaluation of Education (ICFES) in 2014. The analysis was performed by reference group (academic programme) and by education sector (public vs. private). This study is the first application of the partial frontier technique of "order m" developed by Cazals et al. (2002) and the concept of a meta-frontier proposed by O'Donnell et al. (2007) for the analysis of university efficiency with data at the student level. The technique of "order m" can work with data that relate to students in universities and make robust estimates of efficiency. For its part, the concept of a meta-frontier makes it possible to decompose the overall efficiency into the parts corresponding to students and universities.

Among the main conclusions of the analysis, we highlight the following. First, most of the inefficiency of students in the assessment of generic skills in the higher education in Colombia is attributable to the students themselves. Second, a significant number of students would improve their performance in the assessment of skills in each of the reference groups (academic programmes) if they performed as efficiently as those located on the frontier. Third, students in some academic programmes do not fully exploit the characteristics of the institutions to achieve a better performance in the standardized tests. Fourth, the inefficiency share of students varies between academic programmes and university sectors, with students in the private sector more inefficient than those in the public sector in some reference groups (for instance, business administration and related programmes) and less inefficient in others (for instance, engineering and related programmes). Finally, the reference groups of natural sciences in both the public and the private sector, despite not having the highest score for inputs, have the best performance in terms of overall efficiency. This result suggests higher added value of the academic programmes that make up this reference group.

Given the results for the students of academic programmes belonging to the area of education, which have the lowest scores for inputs, a clear policy recommendation is that the Colombian Government, through the Ministry of Education, should create incentives for students with good performance in their high school studies to help them decide to enrol in academic programmes related to education. This is of great importance, because future professionals in this area of knowledge are committed to the academic training (in primary and secondary education) of future college students. Policy makers within universities could implement incentives in the form of scholarships for postgraduate studies to encourage better student performance in "SaberPro" tests and encourage teachers to improve teaching and evaluation methodologies with the goal of improving student competencies. The policymakers of the central government could design policies aimed at stimulating more and better competencies of the students in the baccalaureate and policies for granting scholarships to pursue postgraduate studies and debt forgiveness to students who acquire educational loans to pursue their respective university studies. 


\section{References}

Abbott, M., \& Doucouliagos, C. (2003). The efficiency of Australian universities: a data envelopment analysis. Economics of Education Review, 22(1), 89-97. https://doi.org/10.1016/ s0272-7757(01)00068-1

Abramo, G., Cicero, T., \& D’Angelo, C. A. (2011). A field-standardized application of DEA to national-scale research assessment of universities. Fournal of Informetrics, 5(4), 618-628. https://doi.org/10.1016/j.joi.2011.06.001

Ahn, T., Charnes, A., \& Cooper, W. W. (1988). Some statistical and DEA evaluations of relative efficiencies of public and private institutions of higher learning. Socio-Economic Planning Sciences, 22(6), 259-269. https://doi.org/10.1016/0038-0121(88)90008-0

Battese, G. E., \& Rao, D. S. P. (2002). Technology Gap, Efficiency and a Stochastic Metafrontier Function. International fournal of Business and Economics 1(2), 1-7.

Battese, G. E., Rao, D. S. P., \& O’Donnell, C. J. (2004). A Metafrontier Production Function for Estimation of Technical Efficiencies and Technology Gaps for Firms Operating Under Different Technologies. Fournal of Productivity Analysis, 21(1), 91-103. https://doi.org/10.1023/ b:prod.0000012454.06094.29

Black, H. T., \& Duhon, D. L. (2003). Evaluating and Improving Student Achievement in Business Programs: The Effective Use of Standardized Assessment Tests. Fournal of Education for Business, 79(2), 90-98. https://doi.org/10.1080/08832320309599095

Cazals, C., Florens,J.-P., \& Simar, L. (2002). Nonparametric frontier estimation: a robust approach. Fournal of Econometrics, 106(1), 1-25. https://doi.org/10.1016/s0304-4076(01)00080-x

Chakraborty, K. (2009). Efficiency in Public Education - The role of socio-economic variables. Research in Applied Economics, 1(1), 1-18. https://doi.org/10.5296/rae.vli1.137

Charnes, A., Cooper, W. W., \& Rhodes, E. (1978). Measuring the efficiency of DMUs, European Fournal of Operational Research 2, 429-444.

Cordero, J. M., \& Simancas, R. R. (2013). Separating the school effect from students' performance: Evidence from Spanish PISA data. XXII Jornadas de la Asociación de Economía de la Educación, 1-22. A. Coruña.

Daraio, C., \& Simar, L. (2010). Advanced Robust and Nonparametric Methods in Efficiency Analysis: Methodology and Applications. Springer.

De Borger, B., Kerstens, K., Moesen, W., \& Vanneste, J. (1994). A non-parametric Free Disposal Hull (FDH) approach to technical efficiency: an illustration of radial and graph efficiency measures and some sensitivity results. Swiss fournal of Economics and Statistics 130(4), 647-667.

De Witte, K., Thanassoulis, E., Simpson, G., Battisti, G., \& Charlesworth-May, A. (2010). Assessing pupil and school performance by non-parametric and parametric techniques. Fournal of the Operational Research Society, 61(8), 1224-1237. https://doi.org/10.1057/jors.2009.50

Deprins, D., Simar, L., \& Tulkens, H. (1984). Measuring Labor Inefficiency in Post Offices. In Marchand, P., Pestieau, P., \& Tulkens, H. (Eds.) Concepts and Measurements, Amsterdam, North Holland, 243-267.

Diamond, A. M., \& Medewitz, J. N. (1990). Use of Data Envelopment Analysis in an Evaluation of the Efficiency of the DEEP Program for Economic Education. The Fournal of Economic Education, 21(3), 337-354. https://doi.org/10.1080/00220485.1990.10844680 
Diewert, W. E., \& Fox, K. J. (2014). Reference technology sets, Free Disposal Hulls and productivity decompositions. Economics Letters, 122(2), 238-242. https://doi.org/10.1016/j.econlet.2013.11.026

Gupta, S., Honjo, K., \& Verhoeven, M. (1997). The Efficiency of Government Expenditure: Experiences from Africa. IMF.

Johnes, J. (2006a). Data envelopment analysis and its application to the measurement of efficiency in higher education. Economics of Education Review, 25(3), 273-288. https://doi. org/10.1016/j.econedurev.2005.02.005

Johnes, J. (2006b). Measuring Efficiency: A Comparison of Multilevel Modelling and Data Envelopment Analysis in the Context of Higher Education. Bulletin of Economic Research, 58(2), 75-104. https://doi.org/10.1111/j.0307-3378.2006.00238.x

Johnes, J., \& Taylor, J. (1987). Degree quality: An investigation into differences between UK universities. Higher Education, 16(5), 581-602. https://doi.org/10.1007/bf00128423

Kuah, C. T., \& Wong, K. Y. (2011). Efficiency assessment of universities through data envelopment analysis. Procedia Computer Science, 3, 499-506. https://doi.org/10.1016/j. procs. 2010.12.084

O'Donnell, C. J., Rao, D. S. P., \& Battese, G. E. (2007). Metafrontier frameworks for the study of firm-level efficiencies and technology ratios. Empirical Economics, 34(2), 231-255. https:// doi.org/10.1007/s00181-007-0119-4

Rodgers, T., \& Ghosh, D. (2001). Measuring the determinants of quality in UK higher education: a multinomial logit approach. Quality Assurance in Education, 9(3), 121-126. https://doi. org/10.1108/09684880110399059

Silva Portela, M. C. A., \& Thanassoulis, E. (2001). Decomposing school and school-type efficiency. European Fournal of Operational Research, 132(2), 357-373. https://doi.org/10.1016/ $\underline{\mathrm{s} 0377-2217(00) 00157-0}$

Thanassoulis, E. (1999). Setting Achievement Targets for School Children. Education Economics, 7(2), 101-119. https://doi.org/10.1080/09645299900000010

Thanassoulis, E., Da Conceição, M., \& Silva Portela, A. (2002). School Outcomes: Sharing the Responsibility Between Pupil and School1. Education Economics, 10(2), 183-207. https://doi. org/10.1080/09645290210126913

Thieme, C., Prior, D., \& Tortosa-Ausina, E. (2013). A multilevel decomposition of school performance using robust nonparametric frontier techniques. Economics of Education Review, 32, 104-121. https://doi.org/10.1016/j.econedurev.2012.08.002

Zhang, Y., \& Bartels, R. (1998). The Effect of Sample Size on the Mean Efficiency in DEA with an Application to Electricity Distribution in Australia, Sweden and New Zealand. Fournal of Productivity Analysis 9, 187-204. https://doi.org/10.1023/A:1018395303580

Zoghbi, A. C., Rocha, F., \& Mattos, E. (2013). Education production efficiency: Evidence from Brazilian universities. Economic Modelling, 31, 94-103. https://doi.org/10.1016/j.econmod.2012.11.018 


\section{Annex}

Table A1. Reference groups.

\section{Reference groups}

Accountancy and related

Administration and related

Agricultural sciences

Architecture and urban

Communication, journalism and advertising

Education

Economy

Engineering

Fine arts and designs

Health

Humanities

Law

Medicine

Nursing

Science natural and exact

Science social

Psychology

\section{Academic programmes}

Public accounting; Related studies

Business administration; International trade; International business; Marketing; Business administration international; Hotel and administration tourism

Zootecnia; Veterinary medicine and zootecnia; Business administration agricultural; Veterinary medicine; Agronomy;Related studies

Architecture;Related studies

Social communication; Marketing and advertising; Social communication; Journalism and advertising; Information sciences and documentation; Related studies

Degree in preschool education; Degree in basic education with emphasis on natural sciences and environmental education; Bachelor's degree in children's pedagogy; Degree in social sciences; Degree in basic education with emphasis on social sciences; Degree in mathematics and physics; Degree in Spanish and literature; Related studies

\section{Economy}

Systems engineer; Industrial engineer; Electronic engineering

Civil engineering; Mechanical engineering; Environmental engineering; Electric engineering; Food engineering; Agroindustry engineering; Agronomic engineering; Chemical engineering; Related studies

Industrial design; Graphic and design; Plastic arts; Fashion design; Music; Fine arts; Related studies

Odontology;Physiotherapy; Phonoaudiology; Surgical occupational therapy instrumentation; Nutrition and diet; Occupational health; Bacteriology; Optometrics; Pharmaceutical chemistry; Related studies

Philosophy; History; Theology; Literature; Philosophy and letters; Simultaneous translation; Spanish and classical philology; Modern languages; Related studies

Advocacy; Criminalist; Related studies

Medicine

Nursing

Biology; Math; Physical; Statistics; Geology; Microbiology; Ecology; Chemistry; Related studies

Social work; Sociology; Anthropology; Politics; International relations; Geography; Related studies

Psychology

Source: ICFES. 